\section{Using correlative microscopy for studying and treatment of Mycoplasma infections of the ophtalmic mucosa}

\author{
Del Prete Salvatore ${ }^{1 *}$, Marasco Daniela ${ }^{1}$, De Gennaro Roberto ${ }^{2}$ \\ and Del Prete Antonio ${ }^{3}$
}

'Service Biotech s.r.l., Napoli, Via Monte di Dio 80, 80132, Italy

${ }^{2}$ Department of Earth Sciences, University of Naples Federico II, Naples 80126, Italy

${ }^{3}$ Department of Head and Neck, University of Naples Federico II, 80021 Naples, Italy

\section{Abstract}

Purpose: We have studied in 18-month 21 patients showing kerato-conjunctivitis and/or dermato-blefaritis, where we will find a constant presence of mycoplasma in SEM optical cytology samples. The 21 patients were divided as follows: 7 allergic, 7 alleged allergic and 7 not-allergic, this division it makes between a clinical approach considering clinical history and symptoms. At the first examination, 16 of the 21 patients had a single or multiple infection in which the main pathogenic element was found to be Mycoplasma; the remaining 7, 4 of them were suspected allergic patients, 2 of it, were allergic subjects with the presence of eosinophils or mast cells.

Material and methods: All the study is constructed on citological optical microscopy and citological electron scanning microscopy (SEM) images for demonstrate the efficacy of the SEM in clinical approach at allergic, not allergic and suspected allergic patients.

Therapeutic treatment and Results: Treatment of the allergic and false allergic patients has made with local somministration of galenic composition with ialuronic acid $3 \mathrm{ml}$ and Tetracycline hydrochloride $30 \mathrm{mg}$ and with low level of cortisone and antisthaminic therapy. This treatment is necessary to eradicate the Mycoplasma infection and counteract toxic action of this pathogen on mucosa.

Discussion: After appropriate therapy we note that allergic patients have a greater predisposition to redundancy in infections in the short period (minimum 20 days), while alleged allergic patients have more prolonged infection periods (between 3 and 5 months), with constant presence at low levels of persistent Mycoplasma. The latter continue to show signs and symptoms similar to allergic patients, but with a negative test for tear IgE and absence of eosinophils and/or mast cells, in the optical and SEM samples displayed.

\author{
More Information \\ *Address for Correspondence: Del Prete \\ Salvatore, Service Biotech s.r.I., Napoli, Via \\ Monte di Dio 80, 80132, Italy, Tel: +08119134076 \\ Email: saldelp@gmail.com
}

Submitted: 19 February 2020

Approved: 11 March 2020

Published: 12 March 2020

How to cite this article: Del Prete S, Marasco D, De Gennaro R, Del Prete A. Using correlative microscopy for studying and treatment of Mycoplasma infections of the ophtalmic mucosa. Int J Clin Exp Ophthalmol. 2020; 4: 015-020.

DOI: 10.29328/journal.ijceo.1001028

ORCiD: orcid.org/0000-0001-6004-7781

Copyright: @ 2020 Del Prete S, et al. This is an open access article distributed under the Creative Commons Attribution License, which permits unrestricted use, distribution, and reproduction in any medium, provided the original work is properly cited.

Keywords: Allergic patients; Cytology; Correlative microscopy; Mycoplasma; SEM

\section{Check for updates}

OPEN ACCESS

\section{Introduction}

The study consists of 21 patients, divided into 3 groups, allergic, not-allergic, and alleged allergic, chosen on clinical history and manifestations shown at the first visit; the treatment of 21 patients was carried out over a period of 18 months. After the compilation of the ritual consent in matter of privacy to the execution of the investigations, follows the examination with topconbiomicroscope.TheBiomicroscopevisionallowsaprimary diagnosis, where we have observed 2 allergic conjunctivitis on the allergic group, 3 dermatoblefaro-conjunctivitis, 1 keratoconjunctivitis and a suppurative calazosis in according to the history; in the group of alleged allergic, we found 3 blepharitis/ conjunctivitis, 2 dermatoblefaro-conjiunctivitis of which 1 with punctate keratitis, 1 blepharitis and 1 conjunctivitis; in the last group (third one non-allergic patients) we described, in according with clinical history and signs, 1 dermatoblefaroconjiunctivitis (on type II diabetic abitus), 3 ulcers of which a cogan-like, 2 conjunctivitis and 1 scleritis. Patients are given a tear drop at the level of the tarsal conjunctiva thanks to a special spatula, this secretion is transferred onto a $13 \mathrm{~mm}$ round slide for reading in SEM and on a polarized and colored slide according to the Pappernheim panoptic (MaygrunwaldGiemsa) for reading in optical microscopy; in addition, photos are taken of the biomicroscope with and without fluorescein to document the status quo of patients before therapy.

In conclusion it was observed that patients infected by mycoplasma and having allergic-like habitus presents a different pathological course within the 18 months from 
both allergic and non-allergic subjects. The citology in SEM on the removal of tears therefore becomes irrelevant in the distinction of the inflammatory-infection focus, strongly supporting clinical practice and creating a strong distinction in the development of drug therapy (Figures 1-6).

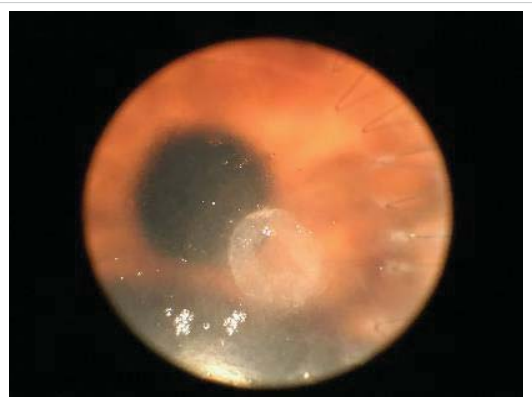

Figure 1: Ulcera before not allergic.

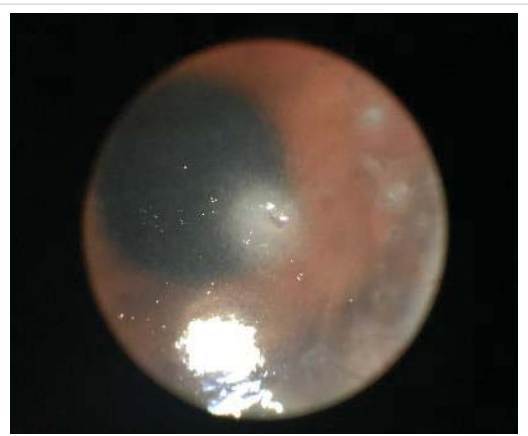

Figure 2: Ulcera after 1 month of therapy Not allergic Patient.

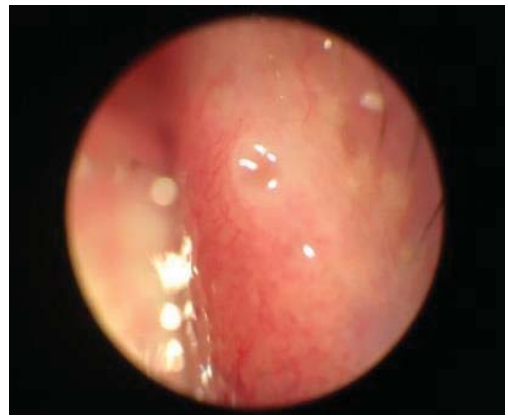

Figure 3: Suspected allergic conjunctiva.

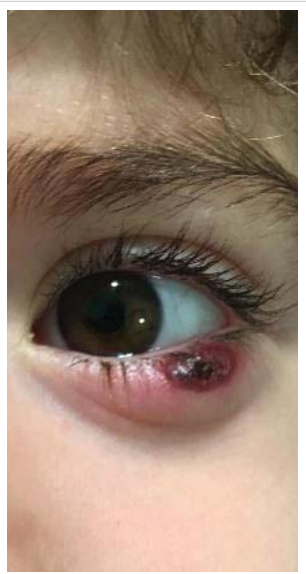

Figure 4: Suspected allergic Chalazion.

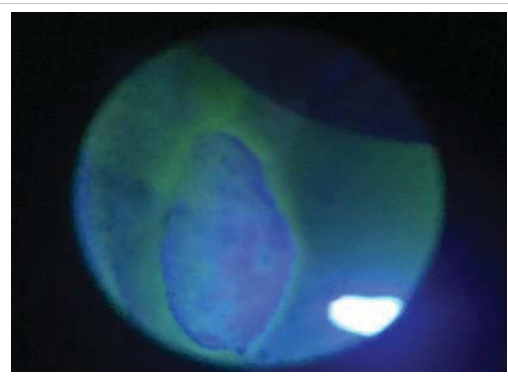

Figure 5: Cornea lesion in allergic.

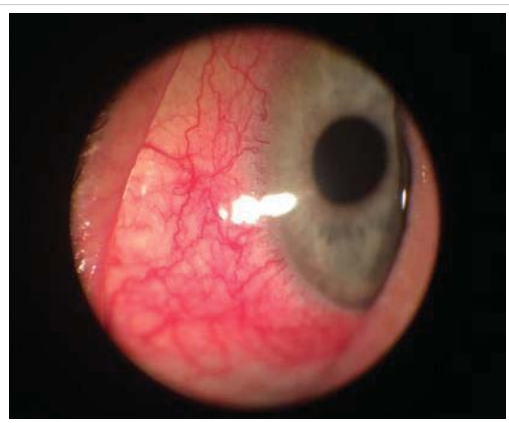

Figure 6: Allergic eye.

\section{Mycoplasma}

As reported in the literature, the mycoplasms [1,2] are the smallest known bacterial forms, they are devoid of cell wall and belong to the class of mollicutes. The most famous mycoplasma that creates disturbances is in the respiratory tract and is usually Mycoplasma pneumoniae. Pneumonia occurs only in $10 \%-15 \%$ of cases out of 12 million, and in most cases (30\%-40\%) involves tracheobronchitis and atypical pneumonia, or $15 \%$ of all pneumonia cases. There are cases of Mycoplasma conjunctivitis in dogs, cats and cattle are documented, so it is known that this type of bacterium can easily attack not only airy but also ocular and urinary tract mucous membranes, but until now there aren't description of micoplasma infection in ocular human surface, because it was so difficult to discover with normal colture tecniques, if it isn't made a specific request. But there are a lot of patients that fall within a significant case history of ocular pathologies of unknown etiology. To identify the Mycoplasma is necessary to inoculate agar media enriched with preformed protein sources, peptones or yeast and cholesterol extracts, in the form of serum. Phenol red is added to the culture medium as a $\mathrm{pH}$ indicator, with thallium acetate and pennicillins to inhibit the growth of other microorganisms. The sample thus inoculated in agar should be placed at 5\% CO2 and 95\% air. The second soil will be passed on a two-phase soil and then passed to agar. The growth of mycoplasma agar colonies takes on a typical fried egg shape. The diagnosis of Mycoplasma infection is mainly performed on clinical grounds. Bacteria can be grown from excreted samples or exudate swabs, but this procedure takes several weeks to produce results. Mycoplasma not invade the epithelium, but adheres to the host cells by means of specialized ends P1, protein adhesin, which adheres to 
neuraminic acid residues and is responsible for the virulence. Once adhered to the tissue they form hydrogen peroxide to dig the underlying mucosa. Some mycoplasmic antigens act as superantigens creating an aggravation of the pathology. There are a lot of methods to identify mycoplasma; starting to biomolecular methods (pCR number of options are available for conclusive detection of the presence of mycoplasmas in escretous fluid) to arrive at confocal vision, where they appear grouped in colonies with a typical fried egg appearance; but in our opinion the best practice is the Electron scanning microscopy, where individual colonial constituents can also be seen and often appear to interact parasitic with other bacterial forms. Under the SEM microscope, they are clearly visible as spherical elements with a diameter between 0.1 and $0.2 \mu \mathrm{m}$, often grouped in circular or dome-shaped aggregates or even in cluster formations. This tecnique can isolate and put in evidence mycoplasma infection without any particular clinical request and with a very short time of investigation considering timing of pCR and colture media grown.

\section{Materials and methods}

\section{Cytological method}

The cytological sampling by scraping technique of the tarsal conjunctiva with a smooth spatula. The conjuctiva mucosal cells and all secretions were placed on slide (Super Frost Plus Menzel - Gläser, Thermo Scientific, Milan, Italy). The cells were then stained according to the panoptic method (3 min in pure May-Grunwald dye [Carlo Erba, Milan, Italy], 6 min in 50\% May-Grunwald dye; 1 min in bidistilled water [Carlo Erba, Milan, Italy]; and $30 \mathrm{~min}$ in Giemsa solution [Carlo Erba, Milan, Italy] diluted 1:10 v/v). The slide was then covered with a \#1 glass cover with dimensions of $24 \mathrm{x}$ $50 \mathrm{~mm}$ and observed under an optical microscope (Nikon Eclipse 50i) at $100 \mathrm{x}$ oil-immersion enlargement. The images were recorded using a Nikon DS1 camera and digitized using a NIS-D elements computer support. SEM method, applied to the practice of scraping cytology of the tarsal conjunctiva placed the secretion of the mucosa on a 13mm DIA round slide (Agar scientific). The sample of round slide is fixed in 2\% gluteraldehyde, then washed in PBS at 7.4 pH for 15 min for 3 times; then treated in OSMIO $4 \%$ for $2 \mathrm{~h}$. Then the samples are 2 times washed in PBS at pH 7.4 [Carlo Erba, Milan, Italy] each at $30 \mathrm{~min}$, finally the sample thus treated is dehydrated in alcohol at increasing concentrations; $30 \%$ at $25 \mathrm{~min}, 50 \%$ at $25 \mathrm{~min}, 70 \%$ at $20 \mathrm{~min}$ and $96 \%$ at $20 \mathrm{~min}$ for 2 times. Once dehydrated the sample is placed in critical-point $\mathrm{CO} 2$ (critical point at $31^{\circ} \mathrm{C}$ and $73 \mathrm{~atm}$ ) (Leica EM CPD300). The preparation was viewed in scanning microscopy with JEOL microscope supplied to the Department of Earth Sciences (DiSTAR) of the University Federico II of Naples. The treatment of the samples allowed to visualize at various magnifications the bacterial species colonizing the ocular mucosa and the typical inflammatory cells; moreover the culture has placed attention on the pathogens involved in the phlogosis of the ocular mucosa of the patient under examination. The using of correlative microscopy put in evidence the correlation between flogosis cells (in evidence with classical citology most) and pathogens in specific Mycoplasma, (in evidence just with scanning electron microscopy); this technique facilitates the diagnosis and the therapeutic treatment.

\section{Therapeutic treatment and results}

The patients performed therapeutic pharmacological treatments considering clinical history and the signs shown with the vision performed at the biomicroscope and in agreement with the results of the cytology carried out in SEM (Scanning electron microscopy). We noted that patients alleged allergic (Tables 1,4) respond differently to therapy than allergic patients (Tables 2,5) and not-allergic patients, in fact the latter solve the inflammatory phenomenon of infection in up to 4 months/ 1 year (Tables 3,6), while for alleged allergy putients and allergy the responses to therapy follow different rhythms, as described above. Therapy for allergic subjects: in accordance with clinical practices, it was made with antihistamines and low levels of cortisone 3 , in combination with therapy with specific antibiotics for pathogens classified in SEM. Then galenic composition with ialuronic acid $3 \mathrm{ml}$ and Tetracycline hydrochloride $30 \mathrm{mg} 1$ drop is administered every 3 hours for the eradication of mycoplasma for 30 days, fluconazole for systemic somministration, for 40 days and PHMB at $0.02 \%$ (distributed by sifi) for up to 1 week to eradicate the Acanthamoeba. This therapy is observed the

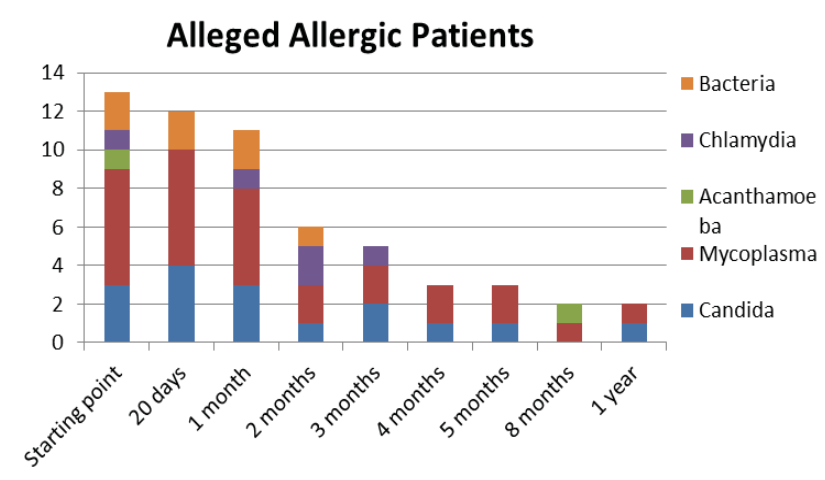

Table 1: Trend of the pathology in the suspected allergic type.

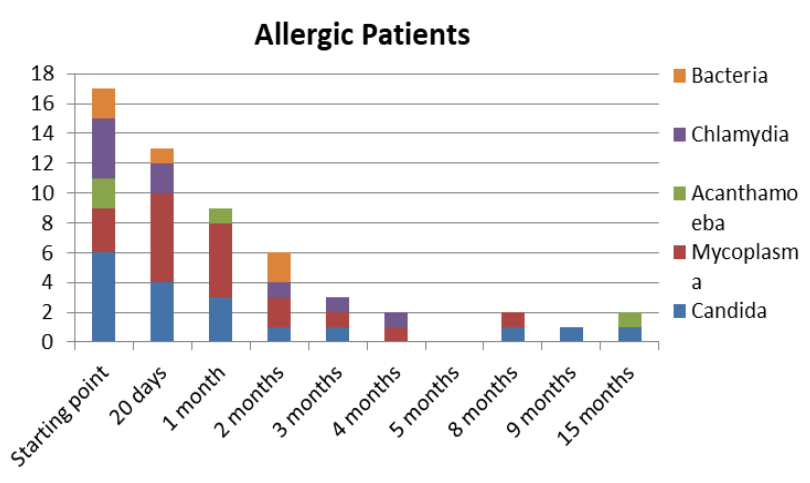

Table 2: Trend of the pathology in the allergic type. 


\section{Not- Allergic Patients}

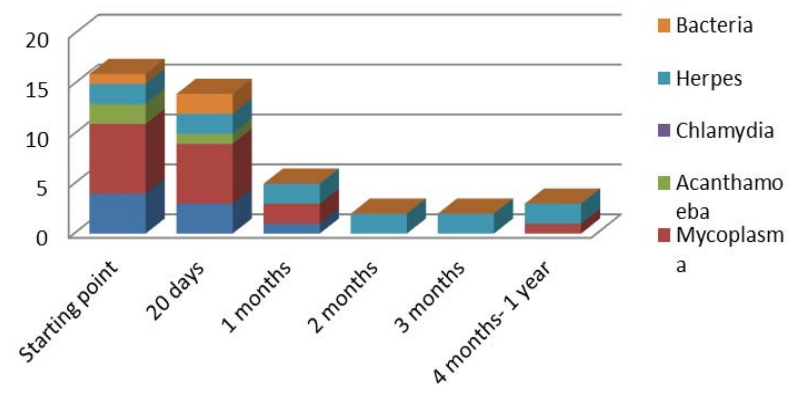

Table 3: Trend of the pathology in the not allergic type.

\section{Mycoplasma In alleged allergic Patients}

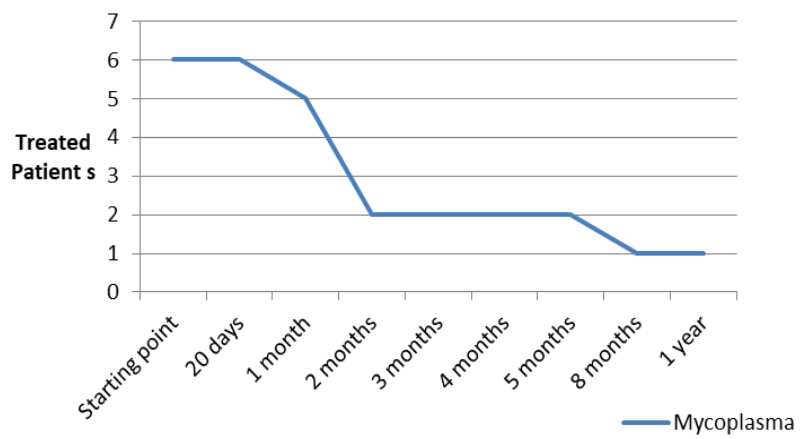

Table 4: Trend of Mycoplasma infection in the alleged allergic type.

\section{Mycoplasma in Allergic Patients}

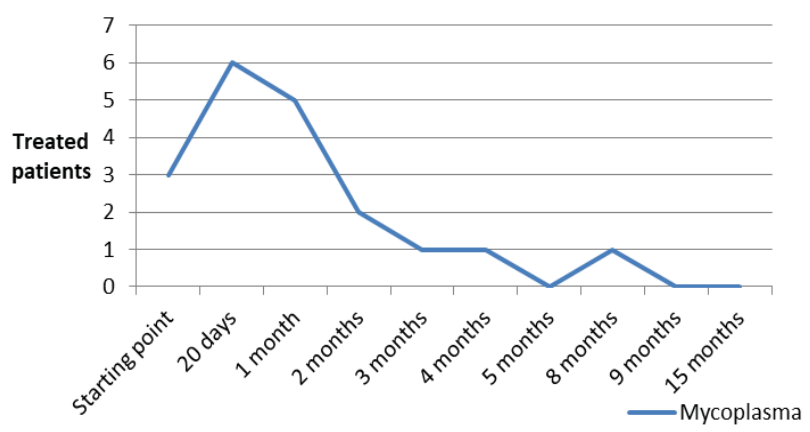

Table 5: Trend of Mycoplasma infection in allergic type.

\section{Mycoplasma in Not - allergic patients}

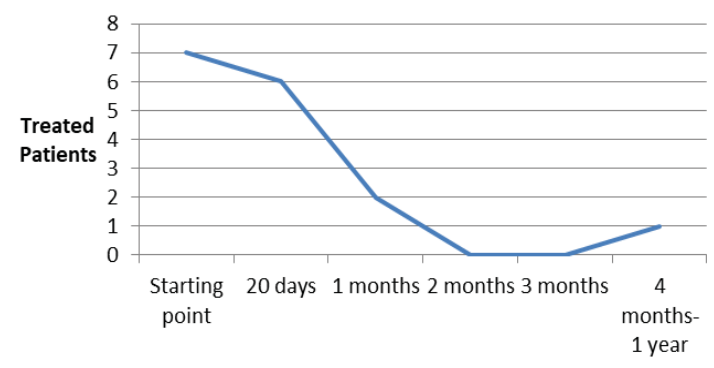

Mycoplasma

Table 6: Trend of Mycoplasma infection in the not allergic type. total eradication of pathogens in subjects declared to be notallergic within 4 months (Figure 7A,B), of starting treatment while a remitting cycle is observed with the onset of different pathogens in subjects with declared allergic habitus, and with an infectious cycle which is closed in the first 20 days of therapy, while a constant presence of mycoplasma [3,4] (Figure 8A-E), even at very low concentrations and a remitting cycle which, however, leads the patient to more lasting treatments over time and to moments of total remission of the symptoms that last even for months (Figure 9A,B).

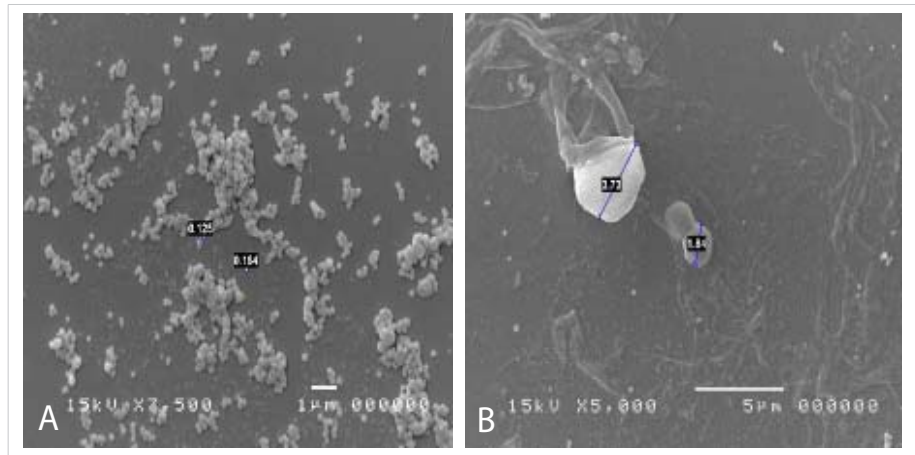

Figure 7: A: mycoplasma expression in tissue. B: Candida and cocci.
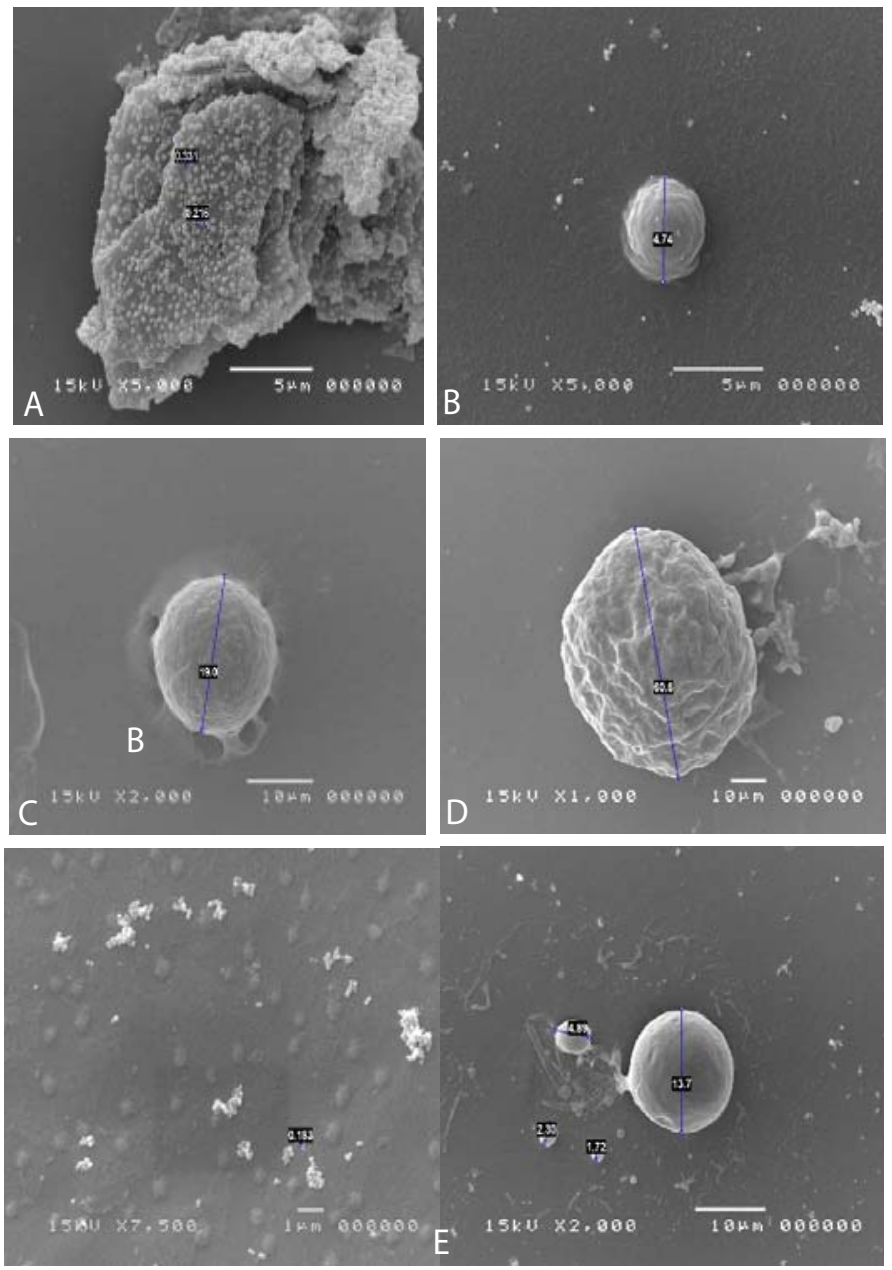

Figure 8: A: Clamydia expression of extracellular forms like elementary corps linked cellular deflagration. B: Candida in spore. C: Mastocyte in degranulation activity. D: Cyst of Acanthamoeba. E: Mycoplasma expression in tissue. 


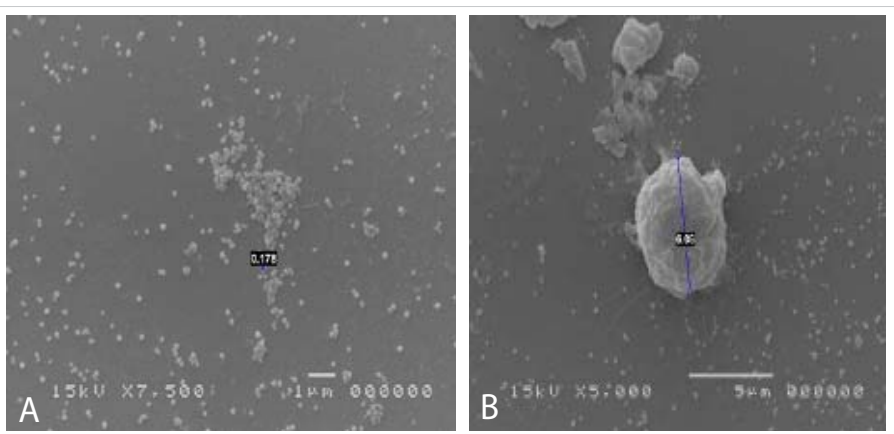

Figure 9: Mycoplasma expression in tissue. B: Limphocyte.

\section{Discussion}

Based on the current literature and publications in the medical field and ophtalmology most, the superantigen function performed by Mycoplasma [5,6] is highlighted. The superantigen Mycoplasma function that explains the different behaviors of the subjects examinated. In fact, the patients belonging to the group of alleged allergic who did not present with tear IgE [7] as shown in the statistical graphs showed a constant, presence of the Mycoplasma, this has generated a chronic latent-type inflammation that manages to mimic an allergic-type response $[7,8]$. From our study we can understand that Mycoplasma has a pivotal role in infections, in fact it is a co-factor in all the described infectious typologies, but in particular in allergic and alleged allergic cases, it creates a phenomenon of stimulation of the immune system [9-12]. The role of superantigene in the case of mycoplasma $[5,6]$ is a fact ascertained, but its presence at the level of the ocular mucosa has so far not been demonstrated except in vertebrate animals $[2,9,10,13]$, where it occupies most of the scientific literature, as a problem bearing in numerous conjunctivitis $[9,13,14]$. SEM, therefore, emphasizes the role of this pathogen and the need to identify its role in ocular pathologies. The interpretation of the data of our study leads to the conclusion that not only does it increase phlogosis, creating a phenomenon of hyperactivity of the immune system (see allergies), but it creates a constant inflammation so as to create a similar allergic response (see alleged allergic), where however, the inflammatory process is no longer supported by eosinophils [7] in the short period (1 year more or less) but by lymphocytic cells only, thus creating a False-allergic abitus [15]. Therefore now the question concerns the treatment of patients presenting Mycoplasma and its eradication; it has been seen that the Mycoplasma behaves differently in the three selected groups, in the nonallergic groups, when the injurious incipit is of high degree, this becomes an opportunistic pathogen, it is eradicated in a short time from the treatment carried out; in allergic patients instead it becomes amplifier and starting point for reinfection phenomena21 even at minimal concentrations; these patients show short periods of shortness, followed by brief periods of recurrence, until the end of the allergic inflammatory cycle. In false allergic patients, there is a constant presence of the Mycoplasma, a persistent activation of the immune system is created $[3,15]$, the mycoplasma becomes irritative spine and a nutritional focus for relapses until the natural end of their infective cycle. Therapeutic treatments must therefore be supported in these latter subjects with mild cortisone $[3,16,17]$ in small quantities and therapies that go to eradicate the "primum movens" of the pathology, namely Mycoplasma [18-26].

\section{Declaration}

\section{Ethical approval}

All procedures performed in studies involving human participants were in accordance with the ethical standards of the institutional national research committee and with the 1964 Helsinki declaration and its later amendments or comparable ethical standards.

\section{References}

1. Rogozinski LE, Alverson BK, Biondi EA. Diagnosis and treatment of Mycoplasma pneumoniae in children. Minerva Pediatr. 2017; 69: 156-160. PubMed: https://www.ncbi.nlm.nih.gov/pubmed/28178776

2. Li P, Zhang Y, Li X, Zhou W, Li X, et al. Mycoplasma hyopneumoniae Mhp597 is a cytotoxicity, inflammation and immunosuppression associated nuclease. Vet Microbiol. 2019; 235: 53-62.

PubMed: https://www.ncbi.nlm.nih.gov/pubmed/31282379

3. Choi YJ, Jeon JH, Oh JW. Critical combination of initial markers for predicting refractory Mycoplasma pneumoniae pneumonia in children: a case control study. Respiratory Research. 2019; 20: 1-9.

4. Hsieh CC, Tang RB, Tsai $\mathrm{CH}$, Chen W. Serum interleukin-6 and tumor necrosis factor-alpha concentrations in children with Mycoplasma pneumonia. J Microbiol Immunol Infect. 2001; 34: 109-112. PubMed: https://www.ncbi.nlm.nih.gov/pubmed/11456355

5. Hodtsev AS, Choi Y, Spanopoulou E, Posnett DN. Posnett Mycoplasma Superantigen Is a CDR3-dependent Ligand for the T Cell Antigen Receptor. J Exp Med. 1998; 187: 319-327.

PubMed: https://www.ncbi.nlm.nih.gov/pubmed/9449712

6. Proft T, Fraser JD. Bacterial superantigens. Clin Exp Immunol. 2003; 133: 299-306.

7. Forte R, Cennamo G, Del Prete S, Napolitano N, Farese E, et al. .Allergic conjunctivitis and latent infections. Cornea. 2009; 28: 839-842. PubMed: https://www.ncbi.nlm.nih.gov/pubmed/19654537

8. Doyle AD, Mukherjee M, LeSuer WE, Bittner TB, Pasha SM, et al Eosinophil-derived IL-13 promotes emphysema. Eur Respir J. 2019; 53. PubMed: https://www.ncbi.nlm.nih.gov/pubmed/30728205

9. Kornspan JD, Tsur M, Tarshis M, Rottem S, Brenner T. Mycoplasma hyorhinis induces proinflammatory responses in mice lymphocytes. J Basic Microbiol. 2015; 55: 679-684

PubMed: https://www.ncbi.nlm.nih.gov/pubmed/25042355

10. Schaunaman N, Sanchez A, Dimasuay G, Pavelka N, Alam R, et al Interleukin 1 Receptor-Like 1 (IL1RL1) Promotes Airway Bacterial and Viral Infection and Inflammation. Infection and Immunity. 2019; 87.

11. Jeong YC, Yeo MS, Kim JH, Lee HB, Oh JW. Mycoplasma pneumoniae infection affects the serum levels of vascular endothelial growth factor and interleukin-5 in atopic children. Allergy Asthma Immunol Res. 2012; 4: 92-97.

PubMed: https://www.ncbi.nlm.nih.gov/pubmed/22379604 
12. Seo Y, Yu BK, Oh YJ, Lee Y, Yoo Y, et al. Increased vascular endothelial growth factor in children with acute Mycoplasma pneumoniae pneumonia and wheezing. Korean J Pediatr. 2008; 51: 487-491.

13. Hawley DM, Moyers SC, Caceres J, Youngbar C, Adelman JS. Characterization of unilateral conjunctival inoculation with Mycoplasma gallisepticum in house finches. Avian Pathol. 2018; 47: 526-530.

14. Fernandez-Aguilar X, Cabezon O, Frey J, Velarde R, Serrano E, et al Long-term dynamics of Mycoplasma conjunctivae at the wildlifelivestock interface in the Pyrenees. PLoS One. 2017; 12: e0186069.

15. Shah PR, Williams AM, Pihlblad, Nischal KK. Ophthalmic Manifestations of Mycoplasma-Induced Rash and Mucositis. Cornea. 2019; 38: 1305-1308. PubMed: https://www.ncbi.nlm.nih.gov/pubmed/31246679

16. Lee KY, Lee HS, Hong JH, Lee MH, Lee JS, et al. Role of prednisolone treatment in severe Mycoplasma pneumoniae pneumonia in children. Pediatr Pulmonol. 2006; 41: 263-268.

PubMed: https://www.ncbi.nlm.nih.gov/pubmed/16437541

17. Radisic M, Torn A, Gutierrez P, Defranchi HA, Pardo P. Severe acute lung injury caused by Mycoplasma pneumoniae: potential role for steroid pulses in treatment. Clin Infect Dis. 2000; 31: 1507-1511. PubMed: https://www.ncbi.nlm.nih.gov/pubmed/11096025

18. Newton JR, Ah-See KW. A review of nasal polyposis. Ther Clin Risk Manag. 2008; 4: 507-512.

PubMed: https://www.ncbi.nlm.nih.gov/pubmed/18728843

19. Waites KB, Xiao L, Liu Y, Balish MF, Atkinson TP. Mycoplasma pneumoniae from the respiratory tract and beyond. Clin Microbiol Rev. 2017; 30: 747-809.

PubMed: https://www.ncbi.nlm.nih.gov/pubmed/28539503
20. Cowan MK. Microbiology: a systems approach. McGraw-Hill. 2018.

21. Fang KN, Wang J, Ni JW. Correlation between Mycoplasma pneumoniae DNA replication level and disease severity in children with severe Mycoplasma pneumoniae pneumonia. Zhongguo Dang Dai Er Ke Za Zhi. 2019; 21: 876-880.

PubMed: https://www.ncbi.nlm.nih.gov/pubmed/31506145

22. Leal Zimmer FMA, Moura H, Barr JR, Ferreira HB. Intracellular changes of a swine tracheal cell line infected with a Mycoplasma hyopneumoniae pathogenic strain. Microb Pathog. 2019; 137: 103717. PubMed: https://www.ncbi.nlm.nih.gov/pubmed/31494300

23. Resende TP, Pieters $M$, Vannucci FA. Swine conjunctivitis outbreaks associated with Mycoplasma hyorhinis. J Vet Diagn Invest. 2019; 31: 766-769.

PubMed: https://www.ncbi.nlm.nih.gov/pubmed/31342882

24. Caruso AA, Viola V, Del Prete S, Leo S, Marasco D, et al. Identification and Characterization of Nasal Polyposis and Mycoplasma Superinfection by Scanning Electron Microscopy and Nasal Cytology with Optical Microscopy: A Case Report. Diagnostics (Basel). 2019; 9. PubMed: https://www.ncbi.nlm.nih.gov/pubmed/31689994

25. Del Prete A, Loffredo C, Carderopoli A, Caparello O, Verde R, et al. Local specific immunotherapy in allergic conjunctivitis. Acta Ophthalmol (Copenh). 1994; 72: 631-634.

PubMed: https://www.ncbi.nlm.nih.gov/pubmed/7887165

26. Khattab RA, Abdelfattah MM. Study of the prevalence and association of ocular chlamydial conjunctivitis in women with genital infection by Chlamydia trachomatis, Mycoplasma genitalium and Candida Albicans attending outpatient clinic Int $J$ ophthalmol. 2016; 9: 1176-1186. PubMed: https://www.ncbi.nlm.nih.gov/pubmed/27588273 